* Corresponding author E-mail address: salim.kadri@yahoo.fr

Article information

Article history: AMS-Volume16-No.2-00146-12

Received 6 February 2012

Accepted 15 March 2012

\section{Mechanical Properties of Thoracic and Abdominal Arteries of Sheep}

\author{
Kadri Salim*, Bouchelaghem Abdelaziz Mahmoud, Lemouchi Karim \\ Laboratory of Industrial Mechanic, (LMI), Department of Mechanical Engineering - University Badji Mokhtar BP12, Annaba-Algeria
}

\section{KEY WORDS}

Mechanical testing, biomaterials, mechanical properties of soft tissues.

\begin{abstract}
An accretion dalliance is accorded by biotechnology, in general, and biomaterials, in particular, in determining the mechanical properties of different biological tissues comprising or composing the living creatures' bodies. Their microscopic and macroscopic structures are complex and mechanical tests can be of a major in studying their mechanical properties [1] [2] [3].

During operation, any blood circulation system is subject to an alternating blood pressure and the constituent organs behave differently. Amongst the rudimentary mechanical tests to characterize thoracic and abdominal arteries, and soft tissues as well - vital components of the blood circulatory system - we find the traction test.

This work focuses on the characterization of thoracic and abdominal arteries, located on the same trunk of a sheep, precisely determining Young's modulus, elasticity constraints, and deformations and break strain.
\end{abstract}

\section{Introduction}

Any soft tissues' pathologies are usually accompanied by an alteration in their mechanical properties [2] [3]. Mechanical properties of the arterial wall ensue from its characteristics of elasticity and contractility. These two factors are tightly correlated to the organization and the state of degeneration of cells and macromolecules that compose the vascular tissue [4] [5].

Due to the fact that tissue pathologies give raise to localized changes in the mechanical properties of the affected tissue, the alteration arterial wall's mechanical properties can be regarded as a parameter for the characterization of vascular tissue. This is what happens in atherosclerotic lesions cases, where the arterial wall thickens and loses its elasticity.

Knowing the mechanical properties of blood vessels has been, for long lasting, recognized as a chief aspect of understanding the cardiovascular system behavior. In 1808, Thomas Young described a relationship between the elasticity of blood vessels and circulatory hemodynamic.

Grand part of Young's researches are based on the nature of the elasticity and[3], in particular, the relationship between the elastic properties of arteries and the arterial wave propagation speed. His work on the elasticity nature led to the development of elasticity modulus concept that bears his name, however.

The elastic behavior of the arterial wall plays an important role in determining the speed of the pressure wave propagation. The benefit of mechanical tests is to identify the mechanical properties and characteristics of any material in such a fashion, 
diseases and issues like deformation, rupture and sudden swelling of the artery are averted.

\section{Testing Methodology}

The tensile (traction) test can precisely determine the targeted mechanical properties: Young's modulus $E$, the elastic limit oélast and breaking stress or. To accomplish that, deformation and strain curves must be drawn. Deformation (Strain) measurements will be carried out by means of extensometer which comprises two blades where the gap between them constitutes the basis of measurement (useful length $\mathrm{L}$ ).

Tensile tests on biological tissue will be made in a in-vitro way (inactive tissue) [6] [7] [8]. Three samples of a sheep thoracic artery will enable us to carry out three tests.

\section{Test Conditions}

-Room temperature (ambient temperature): $20^{\circ} \mathrm{C}$ -Constant Test speed: $100 \mathrm{~mm} / \mathrm{min}$ -Zero clamp slippage.

-Sample specimen-artery tissue from a sheep, shape and dimensions are shown below.
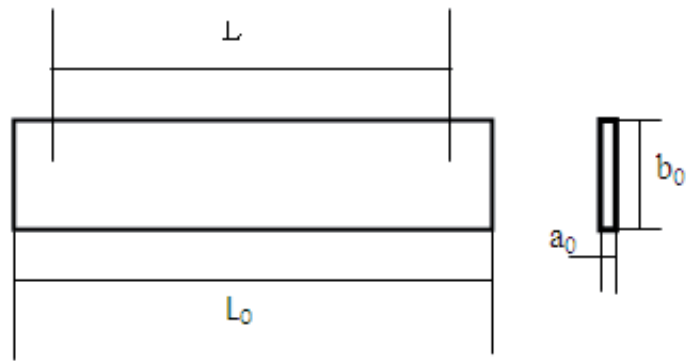

Fig. 1: Physical mode

Effective specimen length $L_{0}=100 \mathrm{~mm}$

Length between the jaws $L=80 \mathrm{~mm}$

Width $b_{0}=20 \mathrm{~mm}$

Thickness of the specimen $\mathrm{a}_{0}=1 \mathrm{~mm}$

- Machine and features: brand ZWICK 1120, "power

Table 1: Mechanical properties obtained. of $2.5 \mathrm{KN}$, jaws maximum displacement $1140 \mathrm{~mm}$ displacement speed $100 \mathrm{~mm} / \mathrm{min}$.

- Software used: Test Expert Version 1.9

Table 2: Mechanical properties obtained.

\begin{tabular}{|l|c|c|c|}
\hline & $\begin{array}{c}\mathrm{E} \\
\left(\mathrm{N} / \mathrm{mm}^{2}\right)\end{array}$ & $\begin{array}{c}\sigma_{\text {elast }} \\
\left(\mathrm{N} / \mathrm{mm}^{2}\right)\end{array}$ & $\begin{array}{c}\sigma_{\max } \\
\left(\mathrm{N} / \mathrm{mm}^{2}\right)\end{array}$ \\
\hline average & 1.27 & 0.12733 & 0.8033 \\
\hline Variance & 0.0021 & 0.0000063 & 0.00958 \\
\hline standard deviation & 0.0458 & 0.00251 & 0.09787 \\
\hline
\end{tabular}

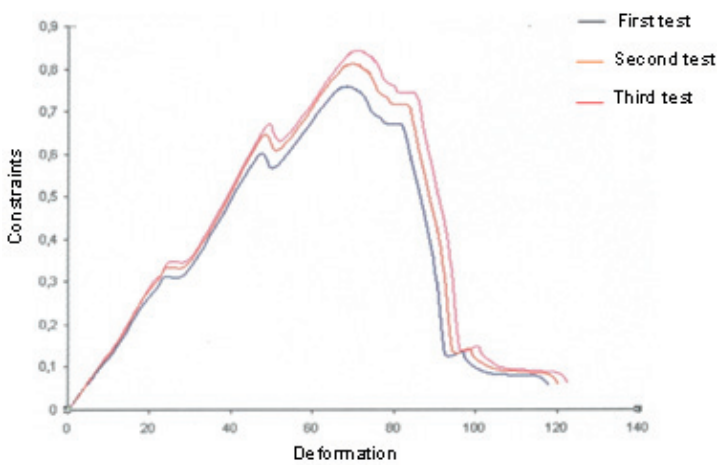

Fig. 2: Stress-strain curves.

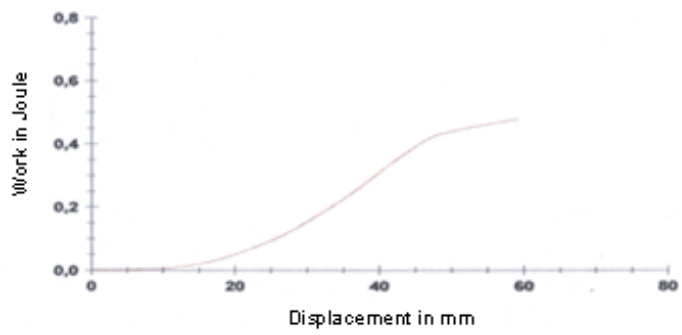

Fig. 3: Working curve in Joule versus displacement.

\section{Concluding remarks}

The shape of the obtained curve corresponds to the classic one of Euler. We perfectly can distinguish (discriminate) three parts: the elastic, almost straight, is characterized by stress and relatively low deformations, the curved section (portion) is featured by fairly high deformations and stresses , the third portion, as it is concerned, is characterized by an abrupt drop of effort corresponding to

\begin{tabular}{|c|c|c|c|c|c|c|c|c|c|}
\hline \multirow{2}{*}{$\begin{array}{c}\mathrm{N} \square \\
\text { testing }\end{array}$} & $a_{0}$ & $\mathrm{~b}_{0}$ & $\mathrm{E}$ & $\sigma_{\text {elast }}$ & $\sigma_{\max }$ & $\varepsilon_{\max }$ & $\varepsilon_{\mathrm{c}}$ & $\sigma_{\mathrm{c}}$ & $\sigma_{\mathrm{r}}$ \\
\hline & $\mathrm{Mm}$ & $\mathrm{mm}$ & $\mathrm{N} / \mathrm{mm}^{2}$ & $\mathrm{~N} / \mathrm{mm}^{2}$ & $\mathrm{~N} / \mathrm{mm}^{2}$ & $\%$ & $\%$ & $\mathrm{~N} / \mathrm{mm}^{2}$ & $\mathrm{~N} / \mathrm{mm}^{2}$ \\
\hline 1 & 1 & 20 & 1.22 & 0.125 & 0.76 & 68.41 & 118.08 & 0.054 & 6.43 \\
\hline 2 & 1 & 20 & 1.31 & 0.130 & 0.84 & 71.15 & 122.80 & 0.060 & 7.428 \\
\hline 3 & 1 & 20 & 1.28 & 0.127 & 0.81 & 69.78 & 120.44 & 0.060 & 7.2864 \\
\hline
\end{tabular}


the maximum stress or tensile strength of the tissue.

The peaks and ranges of the curve imply a reorganization of the structure during the elongation process, because the tissue is made up of three layers (intima, media and adventitia).

The identified and measured features of the tests show that the stresses and deformations are low in the elastic region ( $\varepsilon<15 \%$, up to $0127 \mathrm{~N} / \mathrm{mm}^{2} \sigma$ ) and significant in the other two zones (up $71.15 \varepsilon$ $\%$ o $0.803 \mathrm{~N} / \mathrm{mm}^{2}$ up).

The dispersion (diffusion/ spread) found is rather significant, despite the short test. It is due to the nature of samples which are soft tissues with high contractility.

The activity (work) at the beginning of the displacement is almost nil, it begins to rise from a certain value, thence it finally stabilizes.

The deformation and the recorded activity on the sheep's artery show that the soft type tissue is a non-elastic material.

\section{Nomenclature}

LO: effective specimen Length

L: Length between jaws

b0: Width

a0: Thickness of the specimen

E: Young's Modulus

$\sigma$ : Stress

oc: Conventional Stress

or: Accurate Tensile stress

oelast: Elasticity stress

$\sigma$ max: Maximum stress

$\varepsilon$ : Deformation

$\varepsilon c:$ Conventional Deformation

$\varepsilon$ max: Maximum deformation

\section{References}

[1] N. Assoul, P. Flaud, M. Chaouat, D. Letourneur, I. Battle,"Mechanical properties of rat thoracic and abdominal Aortas", Journal of Biomechanics, Elsevier (2008), 8p.

[2] D. Zelmati, "Study of mechanical properties and toughness of HDPE for the gas pipeline coatings", Thesis of magister, Annaba (2005).

[3] J. J. Wang, K. H. Parker, "Wave Propagation in a Model of the arterial circulation", Journal of Biomechanics, Elsevier (2003), $10 \mathrm{p}$.

[4] Lahbib Soualmi, "Characterizing the elastic properties of the arterial wall by endovascular ultrasonography", PhD (Biomedical Engineering), School Polytechnique de Montreal, October 1998.
[5] Dominique Francois, "Technical engineering, Part I: Mechanical testing of materials", CNRS, Paris.

[6] P. Laurent, "Experimental Methods for Materials Testing cold", cf. p17.

[7] Mc Lean (d),"Mechanical properties of metals", John Wiley, 1967.

[8] Mc Cunntock (FA) and Argon (AS), "Mechanical Behavior of Materials", Addison Wesley (1966). 